\title{
A Novel Tantalum Cluster Chalcohalide $\mathbf{T a}_{4} \mathbf{S}_{1.5} \mathbf{S e}_{7.5} \mathbf{I}_{8}$
}

\author{
Artem L. Gushchin - Maxim N. Sokolov • \\ Pavel A. Abramov • Nina F. Zakharchuk • \\ Vladimir P. Fedin
}

Published online: 12 May 2009

(C) Springer Science+Business Media, LLC 2009

\begin{abstract}
Single crystals of $\mathrm{Ta}_{4} \mathrm{~S}_{1.5} \mathrm{Se}_{7.5} \mathrm{I}_{8}$ are obtained by heating $\mathrm{Ta}, \mathrm{S}, \mathrm{Se}$ and $\mathrm{I}_{2}$ at $300{ }^{\circ} \mathrm{C}$ in 4.0:1.0:8.0:4.4 molar ratio. The structure was determined by X-ray analysis and consists of molecular clusters $\left[\mathrm{Ta}_{4}\left(\mu_{4}-\mathrm{S}\right)\left(\mu_{2}-\mathrm{Q}_{\mathrm{ax}} \mathrm{Se}_{\mathrm{eq}}\right)_{4} \mathrm{I}_{8}\right]$ $\left(\mathrm{Q} \approx \mathrm{Se}_{0.87} \mathrm{~S}_{0.13}\right)$. The tantalum atoms form a square with long Ta...Ta distances (3.26-3.32 $\AA$ ), with four dichalcogenide ligands bridging the Ta-Ta edges and a sulfur atom capping the square. Each Ta atom has two terminal iodine atoms. Raman spectroscopy study shows the presence of the characteristic absorption band at $396 \mathrm{~cm}^{-1}$ which is due to the $\mathrm{Ta}_{4}-\mu_{4}-\mathrm{S}$ vibrations. Cyclic voltammetry shows that $\mathrm{Ta}_{4} \mathrm{~S}_{1.5} \mathrm{Se}_{7.5} \mathrm{I}_{8}$ in solid state undergoes quasi-reversible one-electron oxidation which is metal-centered.
\end{abstract}

Keywords Tantalum $\cdot$ Chalcogen $\cdot$ Chalcohalide $\cdot$ Cluster $\cdot$ Crystal structure

\section{Introduction}

For transition metals of the groups 3-8, tri- and tetranuclear cluster chalcogenide complexes can be obtained, which can be described as having a triangle (Ti, V, Mo, $\mathrm{W}, \mathrm{Re}, \mathrm{Os}$ ) or square (Ln, Ta) of metal atoms, capped by a single chalcogen (Q) atom ( $\mu_{3}$ in the triangular and $\mu_{4}$ in the square planar clusters), and bridged over each side by three (triangular clusters) or four (square planar clusters) tilted $\mu_{2}$-dichalogenide

The online version of the original article can be found under doi: 10.1007/s10876-008-0197-2.

Please note that this article was previously published in Journal of Cluster Science, Volume 19, Number 4. This previous publication was in error. This article was originally slated to appear in this issue.

A. L. Gushchin $(\bowtie) \cdot$ M. N. Sokolov · P. A. Abramov · N. F. Zakharchuk · V. P. Fedin Nikolaev Institute of Inorganic Chemistry, Russian Academy of Sciences, 3 Lavrentiev Avenue, Novosibirsk 630090, Russia e-mail: gushchin_al@yahoo.com 
ligands, so that $\mathrm{M}_{3} \mathrm{Q}_{7}^{\mathrm{n}+}$ or $\mathrm{M}_{4} \mathrm{Q}_{9}^{\mathrm{n}+}$ cluster cores result. These clusters have therefore three different chalcogen sites (one capping, one bridging, residing almost in the $\mathrm{M}_{3}$ (or $\mathrm{M}_{4}$ ) plane (so-called equatorial position) and another bridging above the same plane, on the opposite side from the capping chalcogen (termed axial chalcogens). Thus each $\mu_{2}-\mathrm{Q}_{2}$ ligand is represented as $\mu_{2}-\mathrm{Q}_{\mathrm{eq}} \mathrm{Q}_{\mathrm{ax}}$. In most cases these clusters are obtained by self-assembly reactions [1-4]. This method of preparation poses an interesting problem: will this self-assembly be site-differentiating when two different chalcogen enter the core, preferentially taking a specific position each, or clusters with randomly distributed chalcogen atoms in the core would form? In fact for the trinuclear clusters it seems that the smaller chalcogen always occupies the capping position. This has been proven for the $\mathrm{Re}_{2} \mathrm{O}_{7} / \mathrm{OsO}_{4}-\mathrm{S}-\mathrm{SeCl}_{2}$ systems which always give the $\left\{\mathrm{M}_{3}\left(\mu_{3}-\mathrm{S}\right)\left(\mu_{2}-\mathrm{Se}_{2}\right)_{3}\right\}$ clusters [5], and for the $\mathrm{Mo}(\mathrm{W})-\mathrm{S}-\mathrm{Se}-\mathrm{Br}_{2}$ systems which selectively produce $\left\{\mathrm{M}_{3}\left(\mu_{3}-\mathrm{S}\right)\left(\mu_{2}-\mathrm{Se}_{2}\right)_{3}\right\}$ clusters [A. L. Gushchin and M. N. Sokolov, unpublished results]. It turns out now that the preference of $S$ for the capping position holds also for square clusters. Here we describe a new tetranuclear Ta cluster, $\mathrm{Ta}_{4} \mathrm{~S}_{1.5} \mathrm{Se}_{7.5} \mathrm{I}_{8}$, which contains the planar $\mathrm{Ta}_{4}$ core bridged by one $\mu_{4}-\mathrm{S}$ atom, and by four $\mu_{2}-\mathrm{SeQ}\left(\mathrm{Q} \approx \mathrm{Se}_{0.87} \mathrm{~S}_{0.13}\right)$ units.

\section{Experimental Section}

\section{General Procedures}

High purity Ta and S powders, Se granules and $\mathrm{I}_{2}$ crystals were used. Raman spectra were obtained by means of a Triplimate SPEX spectrometer with a $632.8 \mathrm{~nm}$ line of $\mathrm{He}-\mathrm{Ne}$ laser for excitation. X-ray powder diffraction data were obtained on a DRON-2 powder diffractometer ( $\mathrm{CuK} \alpha$ radiation).

Preparation of $\mathrm{Ta}_{4} \mathrm{~S}_{1.5} \mathrm{Se}_{7.5} \mathrm{I}_{8}(\mathbf{1})$

Ta powder $(0.36 \mathrm{~g}, 2.0 \mathrm{mmol}), \mathrm{S}(0.016 \mathrm{~g}, 0.5 \mathrm{mmol}), \mathrm{Se}(0.32 \mathrm{~g}, 4.0 \mathrm{mmol})$ and small excess of $\mathrm{I}_{2}(0.55 \mathrm{~g}, 2.2 \mathrm{mmol})$ were loaded in a glass ampoule, which was evacuated, flame sealed and heated at $300{ }^{\circ} \mathrm{C}$ (4 days) in a furnace with a small natural temperature gradient. A crop of large single crystals together with a fine powder were obtained. The powder was sifted out leaving the crystals of 1 . The yield was $50 \%$. Element ratio: $\mathrm{Ta}_{4.0} \mathrm{~S}_{1.4} \mathrm{Se}_{7.7} \mathrm{I}_{7.9}$ (EDAX). Raman $\left(\mathrm{cm}^{-1}\right)$ : 396w $\left(\mathrm{Ta}_{4}-\mu_{4}-\mathrm{S}\right), 303 \mathrm{w}, 294 \mathrm{w}, 207 \mathrm{~m}, 204 \mathrm{sh}, 187 \mathrm{~m}, 159 \mathrm{w}, 142 \mathrm{~s}, 140 \mathrm{sh}, 109 \mathrm{~s}, 94 \mathrm{~s}, 86 \mathrm{vs}$, $73 \mathrm{~s}, 70 \mathrm{~s}, 65 \mathrm{~s}, 59 \mathrm{~m}$.

\section{Electrochemistry}

As the title complex is not soluble in common solvents the electrochemical behavior was studied by the method of immobilized solid particles [6]. The cyclic volatmmograms were recorded on a 797 VA Computrance setting (Metrohm, Switzerland). A $10 \mathrm{~mL}$-volume three-electrode cell was employed. As main electrode a paraffin-impregnated graphite (PIGE) with solid particles of the 
complexes under investigation immobilized on it. Immobilization was achieved by rubbing crushed crystals of the complexes into the end surface of PIGE. More details concerning electrode preparation ate to be found in [7, 8]. An $\mathrm{Ag} / \mathrm{AgCl}$ reference electrode, filled with $3 \mathrm{M} \mathrm{KCl}$, was used, and auxiliary electrode was a $\mathrm{Pt}$ wire (6.0343 Metrohm). Background electrolyte was $0.1 \mathrm{M} \mathrm{KCl,} \mathrm{made} \mathrm{by}$ dissolving potassium chloride (Ultrapure) in redistilled water.

\section{X-ray Crystallography}

The diffraction data were collected on a Bruker X8APEX CCD diffractometer with MoK $\alpha$ radiation $(\lambda=0.71073 \AA)$ using $\varphi$-scans of narrow $\left(0.5^{\circ}\right)$ frames. The structure was solved by direct methods and refined by full-matrix least-squares method against $|\mathrm{F}|^{2}$ in anisotropic approximation with SHELXTL programs set. Absorption correction was applied empirically with $S A D A B S$ program $\left(T_{\mathrm{min}} /\right.$ $T_{\max }=0.510$ ) [9-11]. The detailed data are collected in Table 1.

\section{Results and Discussion}

The title compound is obtained by heating the elements in the required stoichiometric ratio at $300{ }^{\circ} \mathrm{C}$ for 4 days. It is easily separated as large black single crystals. The exact composition was determined from the $\mathrm{X}$-ray data. $\mathrm{Ta}_{4} \mathrm{~S}_{1.5} \mathrm{Se}_{7.5} \mathrm{I}_{8}$ is the first compound obtained in the system Ta-S-Se- $\mathrm{I}_{2}$. The structural analogues of $\mathbf{1}$, the selenoiodide $\mathrm{Ta}_{4} \mathrm{Se}_{9} \mathrm{I}_{8}$ (2) and the thiobromide $\mathrm{Ta}_{4} \mathrm{~S}_{9} \mathrm{Br}_{8}$ (3) were recently obtained from the elements [1, 2].

The molecule of $\mathrm{Ta}_{4} \mathrm{~S}_{1.5} \mathrm{Se}_{7.5} \mathrm{I}_{8}$ is shown in Fig. 1. The molecular structure is identical to those of $\mathbf{2}$ and $\mathbf{3}$. Four $\mathrm{Q}_{2}(\mathrm{Q}=\mathrm{Se}, \mathrm{SeS})$ ligands are asymmetrically coordinated to the Ta-Ta edges in the $\mu_{2}-\eta^{2}: \eta^{2}$ manner. The equatorial chalcogen atoms lie almost in the $\mathrm{Ta}_{4}$ plane, and the axial ones deviate from the plane in the opposite direction. The terminal iodine atoms are coordinated slightly asymmetrically. The interatomic distances and some angles are summarized in Table 2. The coordination polyhedron around Ta can be described as pentagonal bipiramid with $\mu_{4}$-S (100\% sulfur occupancy) and one of the I atoms trans to it in the axial position $\left(\mathrm{I}_{\text {trans }}\right)$, and the two groups $\mathrm{Q}_{2}$ and another $\mathrm{I}$ atom $\left(\mathrm{I}_{c i s}\right)$ in the equatorial position. Rather long Ta-Ta distances (3.26-3.32 $\AA$ ) are in agreement with the average Ta oxidation state of +4.5 in this highly electron-deficient cluster. In $\mathrm{Ta}_{4} \mathrm{Se}_{9} \mathrm{I}_{8}$ and $\mathrm{Ta}_{4} \mathrm{~S}_{9} \mathrm{Br}_{8}$ the distances between the $\mathrm{Ta}$ atoms are $3.32-3.39$ and $3.30 \AA$, respectively [1, 2]. The fact that the Ta-Ta distances in $\mathbf{1}$ and $\mathbf{3}$ are almost identical shows that the nature of the $\mu_{4}-\mathrm{Q}$ atom is more decisive for the $\mathrm{M}-\mathrm{M}$ distance than that of the $\mathrm{Q}_{2}$ bridge. The $\mathrm{Ta}_{4}-\mu_{4}-\mathrm{S}$ bond length $(2.43-2.46 \AA)$ is practically the same as found in $\mathrm{Ta}_{4} \mathrm{~S}_{9} \mathrm{Br}_{8}(2.46 \AA$ ) (Table 2). The Se-Se distances correspond to single bond expected for the $\mathrm{Se}_{2}{ }^{2-}$ formalism.

The intermolecular interactions in the crystals of $\mathrm{Ta}_{4} \mathrm{~S}_{1.5} \mathrm{Se}_{7.5} \mathrm{I}_{8}$ and $\mathrm{Ta}_{4} \mathrm{Se}_{9} \mathrm{I}_{8}$ are identical. In both 1 and 2 four shortened non-valent contacts $\mathrm{Se}_{\mathrm{ax}}$...I (3.48-3.59 ̊) are all directed to the same iodine atom so that the molecules are joined into zigzag chains (Fig. 2). 
Table 1 Crystallographic data and details of diffraction experiment for $\mathrm{Ta}_{4} \mathrm{~S}_{1.5} \mathrm{Se}_{7.5} \mathrm{I}_{8}$
Crystal data

Chemical formula

$M_{r}$

Cell setting, space group

Temperature (K)

$a(\AA)$

$b(\AA)$

$c(\AA)$

$V\left(\AA^{3}\right)$

Z

$D_{x}\left(\mathrm{Mg} \mathrm{m}^{-3}\right)$

Radiation type

$\mu\left(\mathrm{mm}^{-1}\right)$

Crystal form, color

Crystal size (mm)

Data collection

Diffractometer

Data collection method

Absorption correction

$$
\begin{aligned}
& T_{\min } \\
& T_{\max }
\end{aligned}
$$

No. of measured, independent and observed reflections

Criterion for observed reflections $I>2 \sigma(I)$

$R_{\text {int }}$

$\theta_{\max }\left(^{\circ}\right)$

Refinement

Refinement on

$R\left[F^{2}>2 \sigma\left(F^{2}\right)\right], w R\left(F^{2}\right), S$

No. of relections

No. of parameters

Weighting scheme

$(\Delta / \sigma)_{\max }$

$\Delta \rho_{\text {max }}, \Delta \rho_{\text {min }}\left(\mathrm{e} \AA^{-3}\right)$

Extinction method

Absolute structure parameter
30.51

$\mathrm{Ta}_{4} \mathrm{~S}_{1.54} \mathrm{Se}_{7.46} \mathrm{I}_{8}$

2377.41

Orthorombic, Pna $2_{1}$

150.0 (2)

14.3541(3)

14.5907(3)

$12.9058(3)$

2702.94(10)

4

5.842

Mo K

35.431

Plate, black

$0.090 \times 0.045 \times 0.025$

Bruker X8Apex CCD detector

Combined $\omega-$ and phi-scans

Empirical (using intensity measurements)

0.165

0.412

24508, 7162, 6629

$F^{2}$

$0.031,0.061,1.052$

7162 reflections

174

Calculated $w=1 /\left[\sigma^{2}\left(F_{o}{ }^{2}\right)\right.$ $\left.+(0.0123 P)^{2}+21.0482 P\right]$ where $P=\left(F_{o}^{2}+2 F_{c}^{2}\right) / 3$

0.001

$2.325,-2.182$

SHELXL

$0.003(7)$

The Raman spectrum of $\mathrm{Ta}_{4} \mathrm{~S}_{1.5} \mathrm{Se}_{7.5} \mathrm{I}_{8}$ shows a weak band at $396 \mathrm{~cm}^{-1}$ that comes from $\mathrm{Ta}-\mu_{4}-\mathrm{S}$ vibrations. The position of this band correlates well with the positions of this vibration in $\mathrm{Ta}_{4} \mathrm{~S}_{9} \mathrm{Br}_{8}\left(407 \mathrm{~cm}^{-1}\right)$ [1]. 
Fig. 1 Molecular structure of $\mathrm{Ta}_{4} \mathrm{~S}_{1.5} \mathrm{Se}_{7.5} \mathrm{I}_{8}$ (1) (ellipsoids of $50 \%$ probability level)

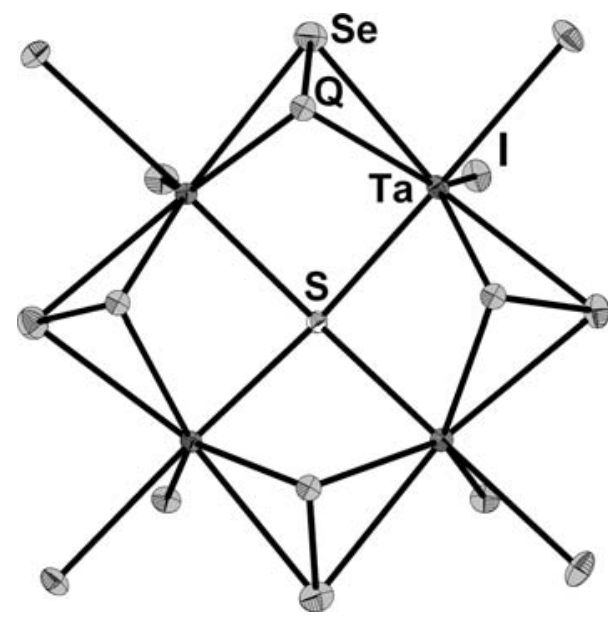

Table 2 Selected bond lengths $[\AA]$ for $\mathrm{Ta}_{4} \mathrm{~S}_{1.5} \mathrm{Se}_{7.5} \mathrm{I}_{8}(\mathbf{1}), \mathrm{Ta}_{4} \mathrm{Se}_{9} \mathrm{I}_{8}(\mathbf{2})$ and $\mathrm{Ta}_{4} \mathrm{~S}_{9} \mathrm{Br}_{8}(\mathbf{3})$

\begin{tabular}{lccccc}
\hline Cluster & $\mathrm{Ta}-\mathrm{Ta}$ & $\mathrm{Ta}-\mu_{4}-\mathrm{Q}$ & $\mathrm{Ta}-\mathrm{Q}$ & $\mathrm{Ta}-\mathrm{Hal}$ & $\mathrm{Q}-\mathrm{Q}$ \\
\hline $\mathrm{Ta}_{4} \mathrm{~S}_{1.5} \mathrm{Se}_{7.5} \mathrm{I}_{8}$ & $3.257(1)-$ & $2.428(3)-$ & $2.603(1)-$ & $2.715(1)-$ & $2.314(2)-$ \\
& $3.318(1)$ & $2.459(3)$ & $2.644(1)$ & $2.785(1)$ & $2.351(2)$ \\
$\mathrm{Ta}_{4} \mathrm{Se}_{9} \mathrm{I}_{8}$ & $3.3231(4)-$ & $2.5705(8)-$ & $2.6003(8)-$ & $2.7282(6)-$ & $2.3367(11)-$ \\
& $3.3924(5)$ & $2.5978(8)$ & $2.6647(9)$ & $2.8076(5)$ & $2.3581(10)$ \\
$\mathrm{Ta}_{4} \mathrm{~S}_{9} \mathrm{Br}_{8}$ & $3.3018(15)$ & $2.461(3)$ & $2.500(4)-$ & $2.471(2)-$ & $2.061(8)$ \\
& & & $2.521(3)$ & $2.483(3)$ & \\
\hline
\end{tabular}

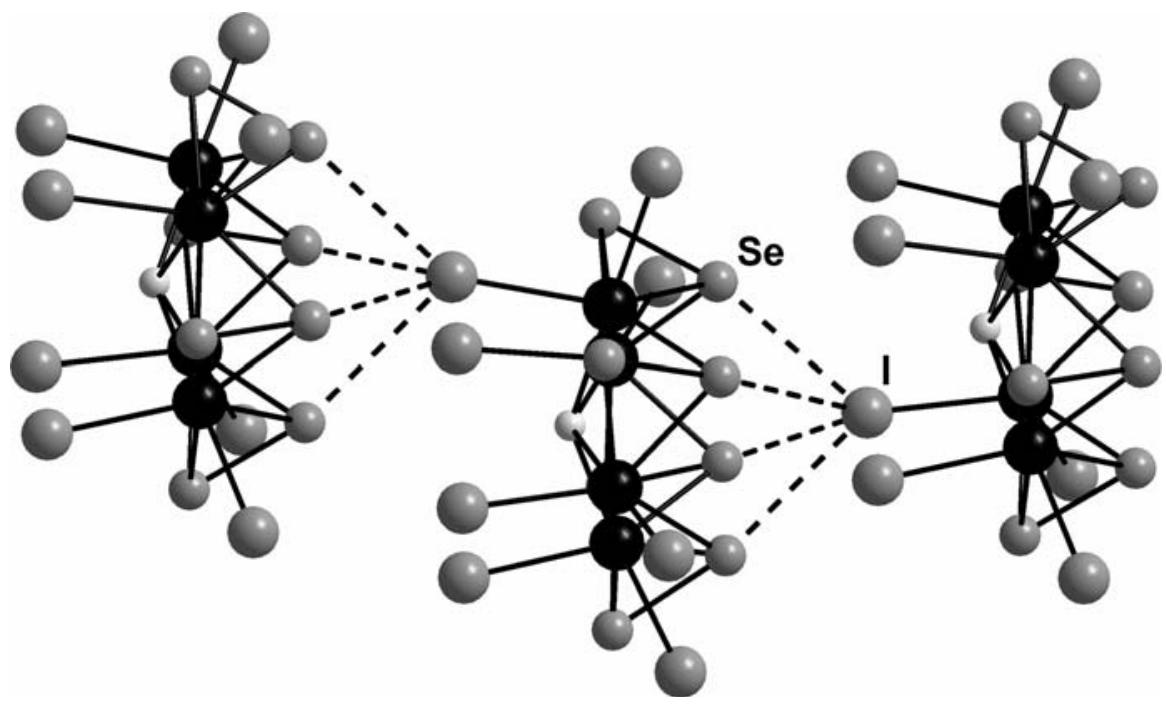

Fig. 2 The chains of molecules in the crystal packing of $\mathrm{Ta}_{4} \mathrm{~S}_{1.5} \mathrm{Se}_{7.5} \mathrm{I}_{8}$. The short interatomic Se...I contacts are shown as dashed lines 


\section{Electrochemistry}

The cyclic voltammograms of $\mathrm{Ta}_{4} \mathrm{~S}_{1.5} \mathrm{Se}_{7.5} \mathrm{I}_{8}$ (1) mechanically immobilized on the surface of PIGE at scan rate of $20 \mathrm{mV} \mathrm{s}^{-1}$ are shown in Fig. 3. In $0.1 \mathrm{M} \mathrm{KCl}$ it exhibits a response of redox couple at $\mathrm{E}_{1 / 2}=\left(\mathrm{E}_{\mathrm{m}}^{\mathrm{a}}+\mathrm{E}_{\mathrm{m}}^{\mathrm{c}}\right)=0.522 \mathrm{~V}$, which is due to the transitions in the metallic core $\left[\mathrm{Ta}_{4}\right]^{18+/(18+n)}$. In order to calculate the number of electrons $(n)$ involved in the rate-determining step, a Tafel plot (Fig. 4) was drawn from background-corrected data taken from the rising part of anodic current-potential curves (where there is no concentration polarization). As is seen from Fig. 4 the Tafel plot indicates one-electron process in the rate-limiting step, assuming transfer coefficients of $\beta=0.5$ with error not exceeding $2 \%$ (the theory requires $0.120 \mathrm{~V} /$ decade slope for one-electron transfer). The Tafel plot was also constructed according to the equation valid for a totally irreversible diffusion process [12], which gives $\mathrm{E}_{1 / 2}=(b / 2) \log v+$ Const., where $\mathrm{b}$ is the Tafel slope. On the basis of this equation, the slope of $\mathrm{E}_{\mathrm{m}} \mathrm{vs} \lg v$ is $b / 2=\partial \mathrm{E}_{\mathrm{m}} / \partial \lg v$. Figure 5 shows cyclic voltammograms of $\mathrm{Ta}_{4} \mathrm{~S}_{1.54} \mathrm{Se}_{7.46} \mathrm{I}_{8}$ with different scan rates and plot a maximum potential vs logarithm of scan rate for the anodic current (see inset). The $\partial \mathrm{E}_{\mathrm{m}} / \mathrm{\partial lg} \mathrm{v}$ is $0.0579 \mathrm{~V} /$ decade, which gives $b=2 \times 0.0579=0.116 \mathrm{~V} /$ decade. This $b$ value also points to one-electron transfer to be a rate-limiting step, if we assume transfer coefficient $\beta=0.5$, with error not exceeding $2 \%$.

Therefore, the redox-process may be described as:

$$
\left[\mathrm{Ta}_{2}^{5+} \mathrm{Ta}_{2}^{4+}\right]^{18+}+\mathrm{e}^{-} \stackrel{-\mathrm{e}^{-}(\text {slowly })}{\stackrel{(\text { flowt })}{\longrightarrow}}\left[\mathrm{Ta}_{2}^{5+} \mathrm{Ta}^{4+} \mathrm{Ta}^{5+}\right]^{19+}
$$

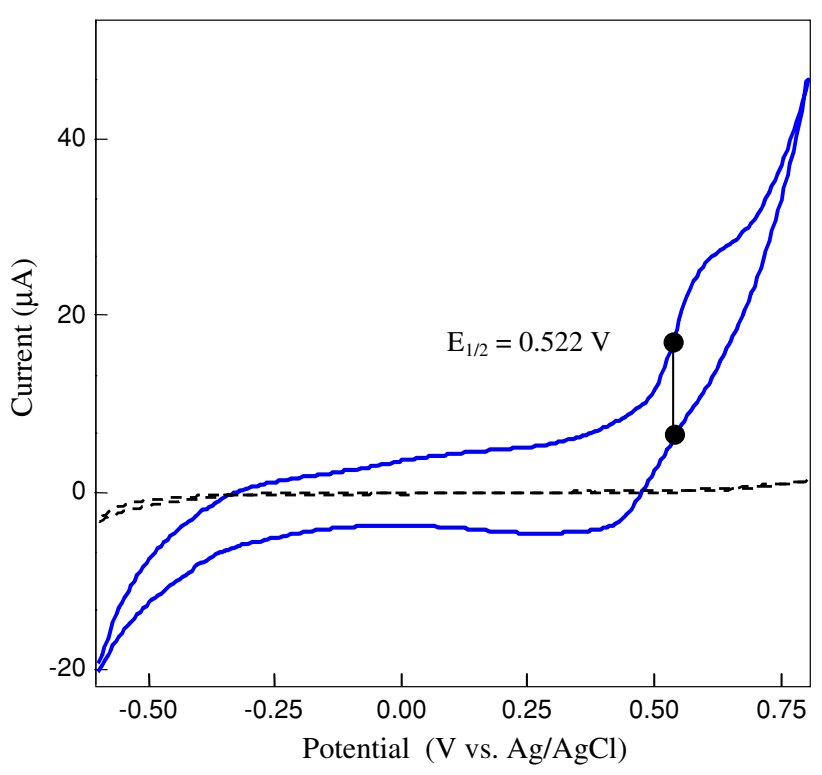

Fig. 3 Cyclic voltammograms of $\mathrm{Ta}_{4} \mathrm{~S}_{1.5} \mathrm{Se}_{7.5} \mathrm{I}_{8}$ (1) mechanically immobilized on the surface of PIGE: background electrolyte $0.1 \mathrm{M} \mathrm{KCl}$ (dashed line); potential route $-0.7 \rightarrow 0.8 \rightarrow-0.7 \mathrm{~V}$; scan rate $20 \mathrm{mV} \mathrm{s}^{-1}$ 
Fig. 4 Tafel plot obtained from anodic current-potential curves recoded for $\mathrm{Ta}_{4} \mathrm{~S}_{1.5} \mathrm{Se}_{7.5} \mathrm{I}_{8}(\mathbf{1})$ as in Fig. 1
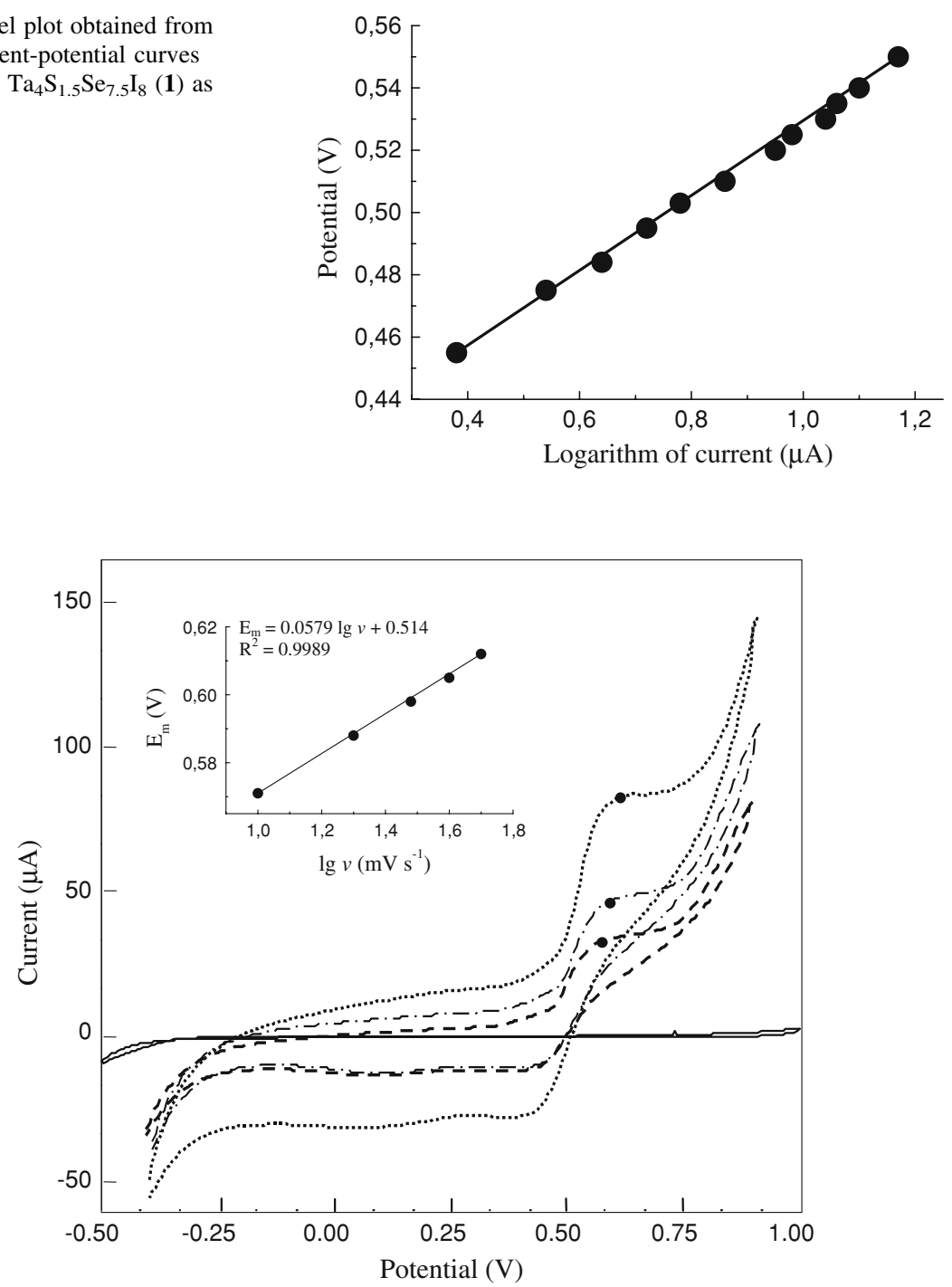

Fig. 5 Cyclic voltammograms of $\mathrm{Ta}_{4} \mathrm{~S}_{1.5} \mathrm{Se}_{7.5} \mathrm{I}_{8}$ mechanically immobilized on the surface of PIGE (solid line): background electrolyte $0.1 \mathrm{M} \mathrm{KCl}$; potential route $-0.3 \rightarrow 0.9 \rightarrow-0.3 \mathrm{~V}$; scan rate $10(-), 20$ $(--)$ and $50(\cdots) \mathrm{mV} \mathrm{s}^{-1}$. (Points denote maximum of oxidation current). Inset plot of maximum potential $\left(\mathrm{E}_{\mathrm{m}}\right)$ versus logarithm of scan rate $(v)$ for the oxidation current at the cyclic voltammograms

The results of the present study demonstrate that under self assembly conditions in a thermodynamically controlled high-temperature synthesis, the lighter chalcogen enters into a position of maximum connectivity. This agrees well with the observations made for the triangular clusters with the $\left\{\mathrm{M}_{3}\left(\mu_{3}-\mathrm{Q}\right)\left(\mu-\mathrm{Q}_{2}\right)_{3}\right\}$ core $[4,5$; A. L. Gushchin and M. N. Sokolov, unpublished results]. Moreover, in the structure of $\mathrm{Cs}_{4}\left[\operatorname{Re}_{6} \mathrm{~S}_{9.45} \mathrm{Se}_{3.55}\right]$ the $\mu_{3}$ positions in the cluster $\left\{\operatorname{Re}_{6}\left(\mu_{3}-\mathrm{Q}\right)_{8}\right\}$ are exclusively 
occupied by the sulfur atoms while Se participates in the $\mu-\mathrm{Q}_{2}$ bridges between the octahedral clusters [13]. In high-temperature syntheses of cuboidal Re clusters, $\left\{\operatorname{Re}_{4}\left(\mu_{3}-\mathrm{Q}\right)_{4}\right\}$ from the elements, when two different chalcogens are introduced in the system, the lighter chalcogen invariably occupies the inner ligand site in the cluster, as for example in $\mathrm{Re}_{4} \mathrm{~S}_{4} \mathrm{Te}_{4}$ and in $\mathrm{Re}_{4} \mathrm{~S}_{4} \mathrm{Cl}_{8}\left(\mathrm{TeCl}_{2}\right)_{4}$ [14, 15]. Thus the preference of $\mathrm{S}$ over $\mathrm{Se}$ and $\mathrm{Te}$ for the bridging position of maximum connectivity seems to be a general rule. A possible explanation for this systematic preference may be that the smallest size of the $\mathrm{S}$ maximizes the $\mathrm{M}-\mathrm{M}$ bonding which is important for the overall cluster stability.

\section{Supporting Information Available}

Crystallographic data in CIF format have been deposited at Fachinformationszentrum Karlsruhe under ICSD number 419404 and can be retrieved be request (crystaldata@FIZ-Karlsruhe.de).

Acknowledgements The authors thank Drs. Alexandr V. Virovets and Eugenia V. Peresypkina for carrying out X-ray diffraction experiment and Technical University of Denmark for an H.C. Ørsted Postdoctoral Fellowship (to ALG).

\section{References}

1. M. N. Sokolov, A. L. Gushchin, P. A. Abramov, A. V. Virovets, E. V. Peresypkina, S. G. Kozlova, B. A. Kolesov, C. Vicent, and V. P. Fedin (2005). Inorg. Chem. 44, 8756.

2. M. N. Sokolov, A. L. Gushchin, A. V. Virovets, E. V. Peresypkina, S. G. Kozlova, and V. P. Fedin (2004). Inorg. Chem. 43, 7966.

3. M. N. Sokolov, V. P. Fedin, and A. G. Sykes (2003). Compr. Coord. Chem. II 4, 768.

4. V. E. Fedorov, Y. V. Mironov, N. G. Naumov, M. N. Sokolov, and V. P. Fedin (2007). Russ. Chem. Bull. 76, 529.

5. S. V. Volkov, Z. A. Fokina, O. G. Yanko, V. I. Pekhnyo, and L. B. Kharkova (2005). Zh. Neorg. Khim. 50, 1244.

6. F. Scholz and B. Meyer in A. J. Bard, and I. Rubenstein (eds.), Voltammetry of Solid Microparticles Immobilized on Electrode Surfaces, Electroanalytical Chemistry. A Series of Advances, vol. 20 (Dekker, New York Basel Hong-Kong, 1998), pp. 1-86.

7. F. Scholz and B. Meyer (1994). Chem. Soc. Rev. 23, 341.

8. N. Zakharchuk, B. Meyer, H. Hennig, F. Scholz, A. Jaworksi, and Z. Stojek (1995). J. Electroanal. Chem. 398, 23.

9. Bruker AXS Inc SADABS (Version 2.11) (Bruker Advanced X-ray Solutions, Madison, Wisconsin, USA, 2004).

10. G. M. Sheldrick SHELX-97 (Universität Göttingen, Germany, 1997).

11. L. J. Farrugia ORTEP-3 (Department of Chemistry, University of Glasgow, 1997).

12. A. J. Bard and I. R. Faulkner, Electrochemical Methods, Fundamentals and Applications (Wiley, New York, 2001).

13. W. Bronger, H.-J. Miessen, R. Neugröshel, D. Schmitz, and M. Spangenberg (1985). Z. Anorg. Allg. Chem. 525, 41.

14. Y. V. Mironov, T. E. Albrecht-Schmitt, and J. A. Ibers (1997). Inorg. Chem. 36, 944.

15. V. E. Fedorov, Y. V. Mironov, V. P. Fedin, H. Imoto, and T. Saito (1996). Acta Crystallogr. Sect. C 52, 1065 . 